\title{
Development and Evaluation of a System for Colonic Delivery of Budesonide
}

\author{
Nikita Maruti Gaikwad*, Karimunnisa Sameer Shaikh, Pravin Digambar Chaudhari \\ Department of Pharmaceutics, Modern College of Pharmacy, Sector 21, Yamuna agar, Nigdi, Pune, Maharashtra 411044, INDIA.
}

\begin{abstract}
In the present study an attempt has been made to address low solubility issue and colonic delivery of Budesonide by developing enteric coated capsule containing Budesonide in a nano emulsifying drug delivery system. Herein, the formulated liquid SNEDDS was transformed to a solid form by spray draying method. Subsequently, it was filled into capsules coated with $\mathrm{pH}$ sensitive polymer, Eudragit S- 100 along with band sealing. However, the drug solubility is an important parameter which was determined in different oils, surfactants and co-surfactants. Ternary phase diagrams were constructed to obtain maximum nano-emulsion area. SNEDDS containing Capmule ${ }^{\circ} \mathrm{MCM}$ L8 as oil, Tween-80 as surfactant and polyethylene glycol 400 as co-surfactant were formulated to get maximum nano-emulsion in the phase diagram. In vitro drug release of the optimized SNEDDS (particle size $116.32 \mathrm{~nm}$ ) revealed enhanced drug release in colonic $\mathrm{pH}$ as compared to pure drug. The developed SNEDDS of budesonide also demonstrated better activity against ulcerative colitis as evidenced by the gradually diminishing morphological damages in the histopathological studies in the TNBS induced ulcerative colitis in rats. Thus, SNEDDS enhanced the solubility of Budesonide while the enteric coating provides its colonic release.

Key words: SNEDDS, Colonic Release, Budesonide, Solubility, In vitro, In-vivo, Ulcerative Colitis.
\end{abstract}

\section{INTRODUCTION}

Budesonide (BUD) is a locally acting corticosteroid with high affinity for glucocorticoid receptors. It offers several therapeutic advantages such as negligible oral bioavailability, rapid clearance and no formation of active metabolites and hence is preferred over old steroids such as hydrocortisone, prednisolone and dexamethasone for the localized treatment of inflammatory bowel diseases. ${ }^{1}$ However, budesonide has poor solubility and bioavailability, a property which limits its dissolution and therapeutic potential. Nevertheless, the solubility of BUD needs much improvement and a formulation for effective drug targeting. Moreover, the Self nano-emulsifying drug delivery system (SNEDDS) is composed of with a peculiar isotropic mixture of lipids and surface coating emulsion. These systems with drugs particles size less than $100 \mathrm{~nm}$ appear optically clear and thermodynamically stable. Amongst the various lipid-based systems, SNEDDS accelerates and improves the permeability rate of drug through biological membrane. SNEDDS spread readily in vivo and motility of the stomach and the intestine causes self-emulsification. ${ }^{2}$ Rapid emulsion formation helps to keep the drug in soluble form whereas the high surface area provided by the small droplets enables more efficient drug transport through the membrane leading to improved oral bioavailability. ${ }^{3,4}$ Thus a SNEDDS containing BUD would enhance its solubility and permeability into the tissue and cells at the site of inflammation.

There are different local and systemic drug delivery system treatments useful in colonic disease like ulcerative colitis, crohn's disease but the challenge the oral drug delivery systems face is to reache up to colon without
Submission Date: 02-02-2017; Revision Date: 17-03-2017; Accepted Date: 13-07-2017

DOI: 10.5530/ijper.51.4.84 Correspondence: N. M. Gaikwad', Department of Pharmaceutics, Modern College of Pharmacy, Sector 21, Yamuna agar, Nigdi, Pune, Maharashtra 411044, INDIA.

Contact no.: 09420806590

E-mail: nikigaikwad09@ gmail.com

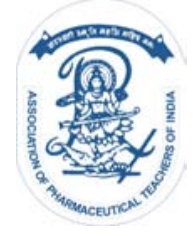

www.ijper.org 
releasing it into stomach and small intestine. Hence, this study was mainly focused to increase the effectiveness of BUD through the concept of an oral enteric coated capsule containing its solid SNEDDS. For colonic delivery of BUD, many approaches such as preparation of BUD loaded microspheres coated with guar gum, microencapsulated cellulosic cores, solid dispersion in dextran, $\mathrm{pH}$ and time dependent polymeric nanoparticles and eudragit coated pellets etc. are available. These reported dosage forms have been formulated with the aim of only targeting drug BUD to colon to enhance its anti-inflammatory activity. The anti-inflammatory activity of BUD is a function of its solubility too. Nevertheless, the solubility of BUD is low and this issue also has to be dealt. The current investigation deserves merit as it addresses both the issues of solubility enhancement and colon targeting by SNEDDS formulation and enteric coating respectively. The formulation of SNEDDS contains Capmule MCM L8, Tween-80 and polyethylene glycol as oil, surfactant and co-surfactant respectively. Subsequently the emulsion form of SNEDDS was spray dried and filled into capsules with coating of $\mathrm{pH}$ sensitive polymer of Eudragit S-100 to achieve colonic targeting. The colon targeted SNEDDS were evaluated for pharmacokinetics and pharmacodynamics parameters. ${ }^{5-8}$

\section{MATERIALS AND METHODS}

\section{Materials}

Budesonide was procured from Lupin pharmaceutical, Inc, Pune, Maharashtra, India. Oils that is Capmule ${ }^{\circledR}$ L8, Cremophor ${ }^{\circledR}$ EL, Captex ${ }^{\circledR}$ 300, Captex ${ }^{\circledR}$ 355, Maisine $^{\mathrm{TM}}$ were purchased from Abitec Ingredient company. Polyetlylene glycol-400, Tween-80 and Tween-20 were received from Loba Chemie Pvt. Ltd, Mumbai. Co-surfactants like Plurol Oleique ${ }^{\circledR}$ and Labrafil M 1944 CS were purchased from Gattefosse, France through Colorcon Asia Ltd, Mumbai. For All others reagents used were of pharmaceutical and analytical grade.

\section{METHODS}

\section{SNEDDS Components}

SNEDDS was composed of three main components such as oil, surfactant and co-surfactant. Maximum solubility of BUD in each of these components was determined by weighing $40 \mathrm{mg}$ drug in $1 \mathrm{ml}$ of different components such as Capmul ${ }^{\mathbb{}}$ MCM L8, Captex ${ }^{\circledR} 300$, Captex $^{\circledR}$ 355, Maisine ${ }^{\mathrm{TM}}$, Labrafil ${ }^{\circledR}$ M 1944 CS and emulsifiers like Tween-80, tween-20, Cremophor ${ }^{\circledR}$ EL, polyethylene glycol-400, Propylene glycol and plurol Olieque ${ }^{\circledR}$ in a $5-10 \mathrm{ml}$ vial. This mixture was stirred for 15 min on magnetic stirrer and further in orbital shaker for $72 \mathrm{~h}$ at $37^{\circ} \mathrm{C}$, followed by centrifugation for $15 \mathrm{~m}$ at $3000 \mathrm{rpm} .1 \mathrm{ml}$ of supernatant obtained was diluted with methanol to make up $10 \mathrm{ml}$ and its absorption measured by UV Spectroscopy at $247 \mathrm{~nm} \cdot{ }^{3-9}$

\section{Diagrammatic Study}

Pseudo ternary phase diagram was built up by water titration method to obtain concentration ranges of oils and S-Mix (a mixture of both Surfactant and co-surfactant). S-mix was prepared in different ratios of 1:1, 1:2, 1:3, 2:1, \& 3:1 (w/w) of surfactant and co-surfactant respectively. An appropriate fixed ratio of S-mix was selected and then it was combined with oil in different ratios of oil-S-Mix such as 1:9, 2:8, 3:7, 4:6, 5:5, 6:4, 7:3, 8:2 and 9:1 (w/w) respectively. As per water titration method, oil and S-mix were taken in above mentioned ratios in pre-weighted vials and slowly water drops were added in to this liquid mixture with the help of burette until clear bluish liquid is seen then stopped adding water. This indicated formulation of a nano emulsion by further adding 2-3 water drops in it, the mixture become opaque. CHEMIX School software was used for construction of ternary phase diagram.

\section{SNEDDS Formulation}

The results obtained from solubility study and ternary phase diagram were used to select concentration of Capmul ${ }^{\circledR}$ MCM L8, Tween ${ }^{\circledR} 80$, polyethylene glycol-400 for the preparation of nano emulsion formulation. The BUD loaded SNEDDS were prepared by dissolving accurately weighed drug (budesonide- $6 \mathrm{mg}$ ) properly in S-mix and oil. The mixture was homogenized the formulation at $40-50^{\circ} \mathrm{C}$, cooled to $25-30^{\circ} \mathrm{C}$ and stored at same temperature.

\section{Evaluation of Liquid SNEDDS Microscopic Examination}

Microscopic study exhibits certain unique characteristics regarding, whether any changes has taken places or not during its storage at normal condition $\left(\right.$ at $30^{\circ} \mathrm{C}$ ); like homogeneity, color, transparency and phase separation.

\section{Percent Transmission Measurement}

Transmission study data revealed stability of the formulation; higher is the percent transmission more stable is the formulation. The formulation $(100 \mathrm{mg})$ was diluted into $100 \mathrm{ml}$ of distilled water, $0.1 \mathrm{~N} \mathrm{HCl}$ and $\mathrm{pH} 7.4$ phosphate buffer solutions. Percent transmission was measured by UV spectrophotometer at $628 \mathrm{~nm}$ in triplicate. $^{10}$ 


\section{Self-emulsification Time Analysis}

Self-emulsification time of SNEDDS was estimated by type II USP dissolution apparatus. The formulation $(500 \mathrm{mg}$ ) was added drop wise into $500 \mathrm{ml}$ distilled water maintained at $37 \pm 0.5^{\circ} \mathrm{C}$ and at $50 \mathrm{rpm}$. Emulsification time was assessed visually. ${ }^{11}$

\section{Determination of Cloud Point}

Cloud point measurement is an essential parameter to form a stable nano emulsion. In this method its determination was done by addition of distilled water to formulation in 1:250 ratio in a water bath at $60^{\circ} \mathrm{C}$. The time required for solution to become opaque and cloudy was noted as the cloud point.

\section{Particle Size Measurement and Polydispersity Index}

Nanophox particle size analyzer instrument was used to measure particle size and polydispersity index of liquid SNEDDS.

\section{Dilution Factor}

Robustness of dilution test was performed by diluting SNEDDS to 10, 100 and 1000 times with dissolution media like $0.1 \mathrm{~N} \mathrm{HCl}, \mathrm{pH} 6.8$ and $\mathrm{pH} 7.4$ phosphate buffer solution. These dilutions were kept for $12 \mathrm{hr}$ and observed for turbidity or phase separation.

\section{Drug stability}

\section{Temperature Stability}

SNEDDS of BUD was kept under ambient room temperature $\left(20-25^{\circ}\right)$ for 3 months and observed for changes in physical stability. The stored samples were evaluated every 4 weeks for appearance, color, drug content and percent transmission.

\section{Centrifugation Stability}

The liquid SNEDDS preparation was subjected to centrifugation ( $5000 \mathrm{rpm}$ for $30 \mathrm{~m}$ ) for observing the changes in homogeneity of nano emulsion. In this method $100 \mathrm{mg}$ formulation was diluted with $100 \mathrm{ml}$ distilled water and then centrifuged.

\section{Spray Drying of Liquid SNEDDS}

It was felt necessary to convert liquid SNEDDS into its most stable solid SNEDDS form. The liquid SNEDDS formulation was added into a solid carrier (Aerosil) previously dissolved in ethanol and stirred for $20 \mathrm{~m}$ at $250 \mathrm{rpm}$. This liquid was subjected to spray drying. Hard gelatin capsules of size 00 were used to fills dry powder and stored at 15 to $25^{0}$ till further use. ${ }^{12}$

\section{Characterization of Solid SNEDDS}

\section{DSC Study}

The differential scanning calorimeter (DSC 823 Mettler Toledo, Japan) was used to study thermogram of pure drug and prepared solid SNEDDS. A closed pierced aluminum pan was used to heat sample (near about 2-5 $\mathrm{mg}$ ) at temperature from $30^{\circ}$ to $180^{\circ} \mathrm{C}$. Heating rate and nitrogen flow rate were maintained at $5^{0} / \mathrm{m}$ and $50 \mathrm{ml} / \mathrm{m}$ respectively to obtain the thermogram.

\section{XRD Analysis}

The powder X-Ray diffractometer was used to studied crystalline nature of pure drug and solid SNEDDS.

\section{Surface Morphological Determination}

Scanning electron microscopy (JSM-6360A, JEOL, Japan) was used to determined surface morphological characteristics like shape and texture of particles. The samples were coated by platinum which was placed on aluminum stub and then this coated sample was observed under scanning electron microscope.

\section{Drug Content Determination}

The solid SNEDDS sample $(10 \mathrm{mg})$ was dissolved in $10 \mathrm{ml}$ methanol and stirred by vortex mixing followed by membrane filtration technique using $0.45 \mu \mathrm{m}$ filter. The concentration of drug was estimated by UV visible spectroscopy using methanol as solvent at $247 \mathrm{~nm}$.

\section{pH Sensitive Polymer Coating Solution}

A polymeric coating solution of Eudragit S-100 was used for coating capsules filled with solid SNEDDS. The coating solution constituted of Eudragit S-100 (15 g), talc $(3 \mathrm{~g})$ and triethyl citrate $(3 \mathrm{~g})$ in isopropyl alcohol $(280 \mathrm{~g})$.

The Eudragit S-100 coated capsule was further given a band seal. Band sealing solution consisted of gelatin type-B (1200 g), Polysobate 80 (10 g), purified water $(4800 \mathrm{~g})$ and colorant (q.s).

\section{In vitro Study}

The release pattern of drug from $\mathrm{pH}$ sensitive polymer coated capsules was evaluated by using type II USP dissolution test apparatus (parameters was set at $50 \mathrm{rpm}$ and $37^{\circ} \mathrm{C}$ ). Drug release from solid SNEDDS and pure drug (Budesonide) was checked by using $900 \mathrm{ml}$ dissolution media of $\mathrm{pH} 1.1$ (0.1 N HCl), pH 6.8 and $\mathrm{pH} 7.4$ (phosphate buffer). Drug released study was performed in $0.1 \mathrm{~N} \mathrm{HCl}$ for $1 \mathrm{~h}, \mathrm{pH} 6.8$ for $3 \mathrm{~h}$ and in $\mathrm{pH} 7.4$ for further time till complete release. About $5 \mathrm{ml}$ sample was withdrawn and replaced with fresh media. Then 
concentration of each sample was determined using UV spectrophotometer at $247 \mathrm{~nm}$.

\section{In vivo Evaluation of Budesonide Loaded SNEDDS in Colitis}

Animal ethics approved protocol referred number is (MCP/IAEC/61/2012).

\section{Treatment Groups}

According to weight of rats they were grouped into three, each group consisting of 3 animals. Group I (normal control group) received $0.5 \mathrm{ml}$ oral saline daily. Group II (colitis control group) received TNBS (Trinitrobenzenesulphonic acid in ethanolic solution) and Group III received BUD loaded SNEDDS formulation. Ulceration was induced by TNBS and after $24 \mathrm{~h}$ of induction, rectal administration of solid SNEDDS (reconstituted) was given daily to the rats up to 7 days. ${ }^{13}$

\section{Induction of Ulcerative Colitis}

Colonic ulcer was produced in anesthetic rat by using $20 \mathrm{mg}$ TNBS dissolved in $0.5 \mathrm{ml}(40 \% \mathrm{v} / \mathrm{v})$ ethanol. Intra colonic ulcer was produced by administration of TNBS solution which was introduced with the help of infant feeding tube $(25 \mathrm{~cm}$ long) rectally. Rats were held upsidedown with the help of tail for 1-2 $\mathrm{m}$ to minimize outflow of the dose and were then returned to their cages until recovery. The above mentioned method was used for control group also by giving normal saline solution. After the 3 days treatment of TNBS, treatment group and normal group rats were sacrificed at $4^{\text {th }}$ day. Ulcer induced colons were analyzed histopathologically.

\section{Histopathological Determination}

Thin sections of epithelium tissues of colon $(6 \mu \mathrm{m})$ were stained with conventional method using staining agent (hematooxylin and eosin). Then interpretation of slides was done after microscopic examination.

\section{RESULT AND DISCUSSION}

\section{Formulation and Development of SNEDDS Solubility Study}

The components such as oils, surfactant and co-surfactant, in which the drug has maximum solubility were identified in this study. The importance of this study was to improve drug loading efficiency and reduce final volume of SNEDDS formulation. ${ }^{14}$ The oils investigated were capable of solubilising remarkable amounts of BUD. As seen in Table 1, from selected oils, Capmul ${ }^{\circledR}$ MCM L-8 could significantly solubilise in higher amount of BUD (38.28 $\pm 0.02 \mathrm{mg} / \mathrm{ml})$. Hence, it was selected as ideal oil for SNEDDS formulation.

Surfactants are amphiphilic in nature and due to their high HLB and hydrophilicity most hydrophobic drugs are solubilized readily. Non-ionic surfactants were preferred for formation of SNEDDS due to less toxicity and due to effectiveness at all $\mathrm{pH}$ effectiveness. Also, surfactants of HLB 12-18 were chosen to form stable $\mathrm{o} / \mathrm{w}$ nano emulsion. Among all the surfactants tested, Tween 80 had maximum solubilization potential for BUD and was selected as the surfactant for formation of SNEDDS.

Co-surfactants help to reduce the concentration of surfactants which are otherwise harmful in maximum amount. They also provide flexibility to interfacial film to attain the required curvature to form nano emulsion. The co-surfactants screened included PEG 400, propylene glycol and Plurol Olieque ${ }^{\circledR}$. BUD showed maximum solubility in PEG-400 and hence it was used for formation of SNEDDS.

\section{Construction of Ternary Phase Diagram}

The final ratio of selected components was playing an essential role in stability of formulation. By constructing ternary phase diagram components ratio (oil:surfactant: co-surfactant) was optimized. The ratio of oils and S-mix were taken as 1:9, 2:8, 3:7, 4:6, 5:5, 6:4, 7:3, 8:2 and 9:1. The ratio of surfactant:Co-surfactant to obtain SNEDDS (designated as S-Mix) studied were as 1:1, 2:1, 3:1, 1:2, 1:3 (data not shown). It was found that S-mix:oil ratio of 3:7 showed excellent stability. Hence, this ratio was finalized to further check effect of different S-mix combinations. All the components in different combination are listed in Table 2. If nano-emulsion region was obtained then it is mentioned as $\mathrm{NE}$ and if nano-emulsion region was not obtained then it is mentioned as NO.

In Figure 1 ternary phase diagram, colored region shows formation of nano emulsion region. A mixture of surfactant: co-surfactant i.e S-mix of Tween 80: Polyethylene glycol-400 in the ratio of 1:1 along with Capmule ${ }^{\circledR}$ MCM L8 oil in the ratio of 3:7 showed maximum nano emulsion area than others and hence were selected as the final composition of the BUD SNEDDS.

\section{Preparation of drug loaded SNEDDS}

BUD loaded SNEDDS were prepared in varying compositions to study the effect of drug loading on the performance of the oils, S-Mix and their ratios selected 
Table 1: Solubility of Budesonide in different oils, surfactant and co-sufactant components

\begin{tabular}{|c|c|c|c|c|c|}
\hline Oils & $\begin{array}{c}\text { Solubility } \\
(\mathbf{m g} / \mathbf{m l})\end{array}$ & Surfactant & $\begin{array}{c}\text { Solubility } \\
(\mathbf{m g} / \mathbf{m l})\end{array}$ & Co-surfactant & $\begin{array}{c}\text { Solubility } \\
(\mathbf{m g} / \mathbf{m l})\end{array}$ \\
\hline Capmule $^{\circledR}$ MCM L8 & $38.23 \pm 0.04$ & Cremophor $^{\circledR} \mathrm{EL}$ & $14.47 \pm 0.10$ & Plurol olieque $^{\circledR}$ & $32.80 \pm 0.11$ \\
\hline Labrafil $^{\circledR}$ M 1944 CS & $22.85 \pm 0.09$ & Tween 80 & $38.46 \pm 0.17$ & PEG-400 & $33.95 \pm 0.12$ \\
\hline Captex $^{\circledR} 355$ & $16.85 \pm 0.06$ & Tween 20 & $19.39 \pm 0.07$ & & \\
\hline Captex $^{\circledR} 300$ & $25.33 \pm 0.06$ & & & & \\
\hline Maisine $^{\mathrm{TM}}$ & $13.39 \pm 0.08$ & & & & \\
\hline
\end{tabular}

\pm Standard deviation

Table 2: Observations for nano emulsion region in the constructed ternary phase diagrams

\begin{tabular}{|l|c|c|c|c|c|}
\hline Oil & Surfactants & Co-surfactants & $\begin{array}{c}\text { S-mix } \\
\text { Ratio }\end{array}$ & $\begin{array}{c}\text { Oil to S-mix } \\
\text { ratio }\end{array}$ & $\begin{array}{c}\text { Nano-emulsion } \\
\text { region (NE) or } \\
\text { None }\end{array}$ \\
\hline Capmule MCM L8 & Tween 80 & Polyethylene glycol-400 & $1: 1$ & $1: 9$ & NE \\
\hline Capmule MCM L8 & Tween 80 & Polyethylene glycol-400 & $1: 1$ & $2: 8$ & NE \\
\hline Capmule MCM L8 & Tween 80 & Polyethylene glycol-400 & $1: 1$ & $3: 7$ & NE \\
\hline Capmule MCM L8 & Tween 80 & Polyethylene glycol-400 & $1: 1$ & $4: 6$ & NE \\
\hline Capmule MCM L8 & Tween 80 & Polyethylene glycol-400 & $1: 1$ & $5: 5$ & NE \\
\hline Capmule MCM L8 & Tween 80 & Polyethylene glycol-400 & $1: 1$ & $6: 4$ & None \\
\hline Capmule MCM L8 & Tween 80 & Polyethylene glycol-400 & $1: 1$ & $7: 3$ & None \\
\hline Capmule MCM L8 & Tween 80 & Polyethylene glycol-400 & $1: 1$ & $8: 2$ & None \\
\hline Capmule MCM L8 & Tween 80 & Polyethylene glycol-400 & $1: 1$ & $9: 1$ & None \\
\hline
\end{tabular}

\begin{tabular}{|c|c|c|c|}
\hline \multicolumn{4}{|c|}{ Table 3: Composition of formulations } \\
\hline Formulation code & $\begin{array}{c}\text { Amount of Capmule } \\
\text { MCM L8 oil } \\
\text { (mg) }\end{array}$ & $\begin{array}{c}\text { Amount of Tween 80: Polyethylene } \\
\text { glycol-400 (surfactant:cosurfactant) } \\
\text { (mg) }\end{array}$ & $\begin{array}{c}\text { Amount of Budesonide } \\
\text { drug (mg) }\end{array}$ \\
\hline F1 & 100 & 900 & 06 \\
\hline F2 & 200 & 800 & 06 \\
\hline F3 & 300 & 700 & 06 \\
\hline F4 & 400 & 600 & 06 \\
\hline F5 & 500 & 500 & 06 \\
\hline
\end{tabular}

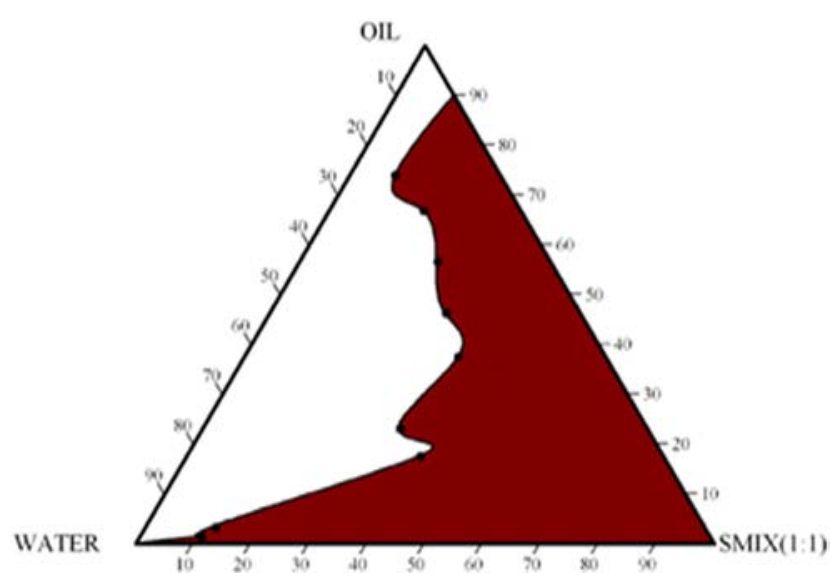

Figure 1 (a):Ternary phase diagram of a mixture of surfactant:co-surfactant in different ratio with oil. (Colored region indicated nanoemulsion areas) 1 (a):Pseudo-ternary phase diagram of Smix 1:1 ratio
WATER

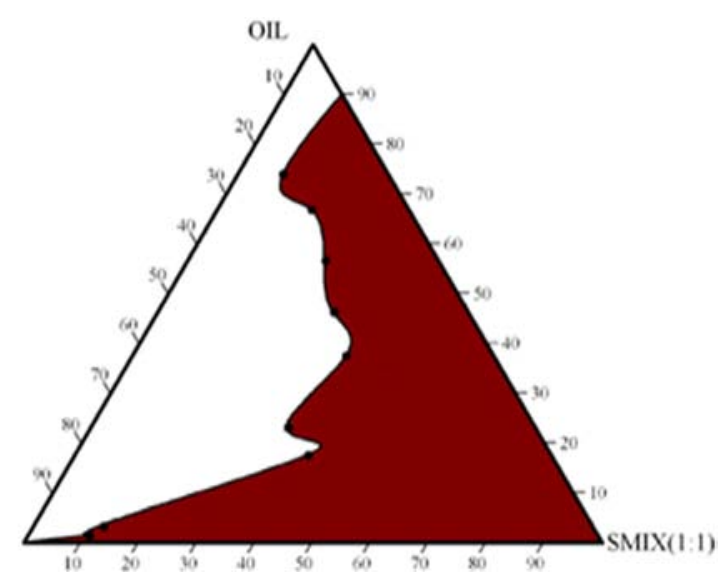

Figure 1 (b): 1 (b): Pseudo-ternary phase diagram of Smix 1:2 ratio 


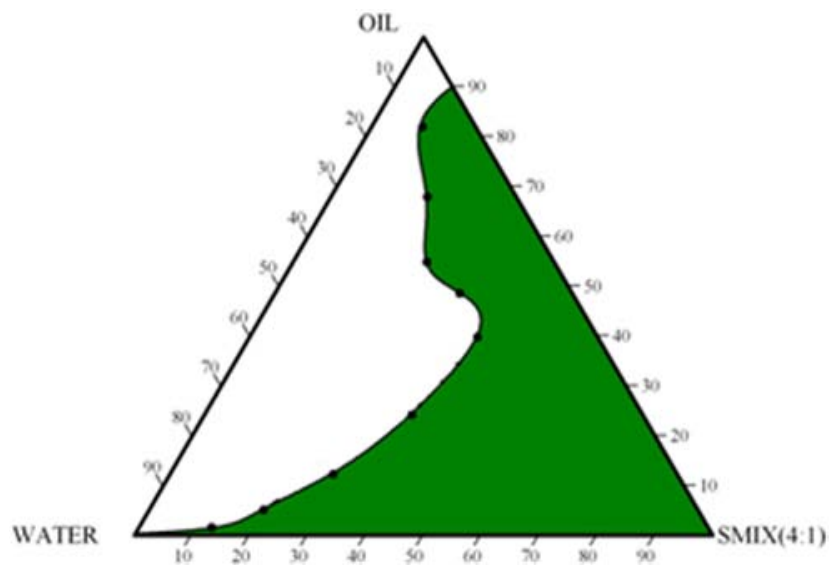

Figure 1 (c): Pseudo-ternary phase diagram of Smix 1:3 ratio.

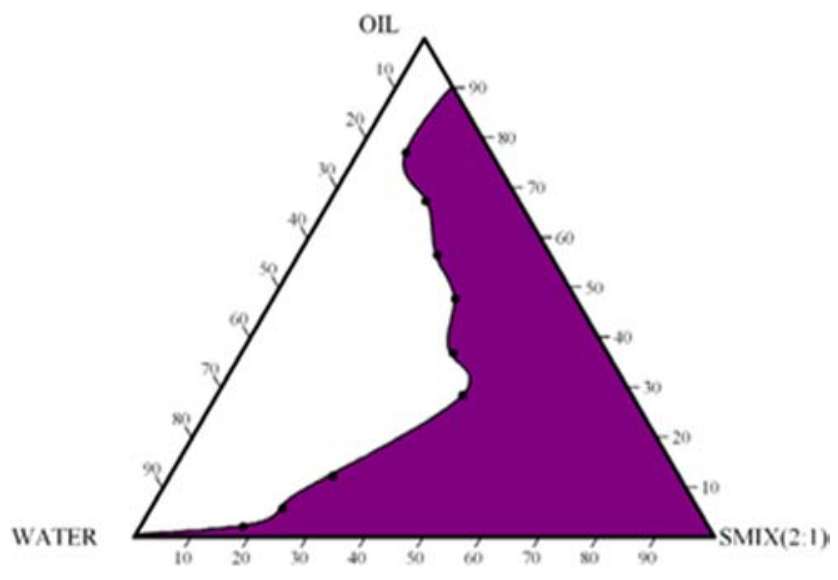

Figure 1 (d) : Pseudo-ternary phase diagram of Smix 2:1ratio.

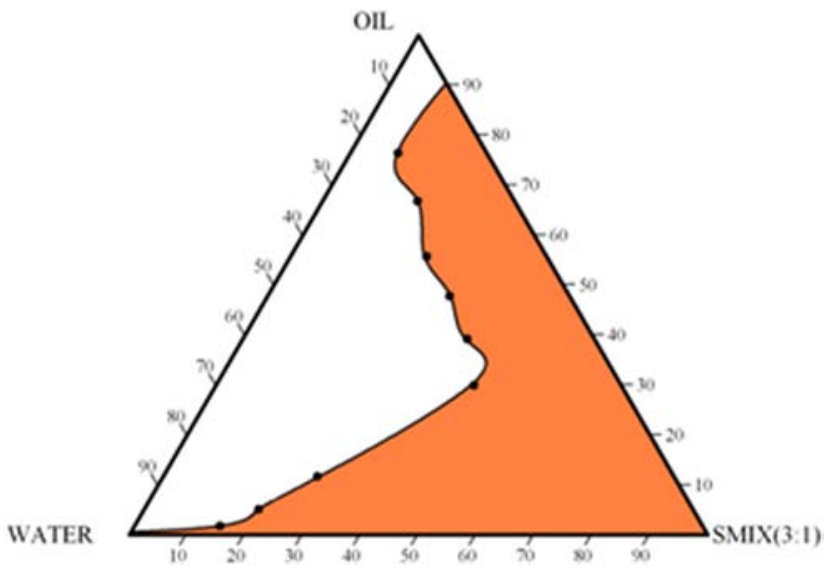

Figure 1 (e) : Pseudo-ternary phase diagram of Smix 3:1 ratio.

in the preceding section. The compositions of formulations $\mathrm{F} 1$ to $\mathrm{F} 5$ is given in Table 3.

\section{Characterization of Liquid SNEDDS}

\section{Macroscopic Evaluation}

After storing the liquid SNEDDS at $30^{\circ} \mathrm{C} \pm 2^{\circ} \mathrm{C}$ for 3 months, no phase separation had occurred and formulation was seen to be clear and homogeneous.

\section{Transmission Test}

The percent transmittance of each formulation after dilution with $0.1 \mathrm{~N} \mathrm{HCl}, \mathrm{pH} 6.8$ and 7.4 phosphate buffer was checked with the help of UV-spectrophotometer at $628 \mathrm{~nm}$ (Figure 2). A higher concentrations of oil in formulation produced low percent transmission and slightly cloudy dispersions were obtained. When concentration of surfactant was increased it resulted in a proportionate increase in percent transmission and produced a clear solution. The percent transmittance of formulations, F1-F5 (composition as in Table 3) was above 95\% in all media tested indicating that the droplet size was in nanometer range and a transparent nanoemulsion was formed. The maximum percent transmission had shown optically clear nano emulsion formulation.

\section{Robustness Test}

The liquid SNEDDS were diluted with dissolution media (0.1 N HCl, pH 6.8 and 7.4 phosphate buffer) except F4 and F5; remaining formulations did not show any phase separation, precipitation and cloudiness in 24h. SNEDDS formulations were exposed to different media in an attempt to mimic the in vivo condit4ion. Each SNEDDS formulation except F4 \& F5, on dilutions with distilled water, $0.1 \mathrm{~N} \mathrm{HCl}$, and phosphate buffer $\mathrm{pH}$ 6.8, phosphate buffer $\mathrm{pH} 7.4$ did not show signs of precipitation, cloudiness or separation after $24 \mathrm{~h}$. Slightly turbidity observed in F4 and F5 formulation may have been due to the higher percentage of oil.

\section{Self-emulsification Analysis}

Need of this analysis was to find efficiency of nano emulsion formulation. On gentle agitation, the time required to self emulsification of SNEDDS was found to be $2 \mathrm{~m}$ and all the batches showed emulsification time of not more than $2 \mathrm{~m}$.

\section{Cloud Point Measurement}

Most of the hydrophilic surfactant showed turbidity above certain temperature that is known as cloud point. As the temperature increased, phase separation appears and drug absorption gets affected due to dehydration of ingredients of formulation. Hence, to avoid this, the formulation must be stabilized to above $37^{\circ} \mathrm{C}$ (above normal body temperature). It was found that all formulation showed cloud point above $60^{\circ} \mathrm{C} .{ }^{16}$

\section{Droplet Size Determination}

The average globule size of micro emulsion formed by F1-F3 was between $90-94 \mathrm{~nm}$ (Table 4). The small droplet size is probably a result of more surfactant content relative to that of oil present on oil-water interface. 
Polydispersity index for F1-F3 was found to be 0.069 to 0.128 indicating uniformity of droplet size. ${ }^{17}$

\section{Optimized Batch}

F3 batch was finalized on the basis of highest percent transmittance, higher amount of S-mix, lower mean droplet size and polydispersity index. Optimized components are shown in Table 5. Its droplet size distribution is shown in Figure 3.

\section{Stability}

Although, the stability studies directly co-relates with shelf life of the formulation it is also an important to study temperature stability by subjecting optimized batch to variant stress conditions like temperature (at $37-40^{\circ}$ ) and centrifugation (at $5000 \mathrm{rpm}$ for $30 \mathrm{~m}$ ). The formulation F3 did not show evidence of phase separation or flocculation or precipitation at $37-40^{\circ}$ temperature.

\section{Evaluation of Solid SNEDDS}

The stability of solid formulation is more as compared to liquid formulation reported by Mishra et al., 2009. ${ }^{18}$ Hence, with the help of spray drier machine, liquid SNEDDS was converted into its solid form. The BUD loaded solid SMEDDs was characterized for the following study:

\section{DSC Study}

If the drug showed sharp endothermic peak, then it was in its crystalline form. Here, pure Budesonide DSC thermogram showed endothermic peak at $234.3^{\circ}$ and there was no drug peak found in the solid SNEDDS of budesonide, indicating loss of crystallinity of drug. The SNEDDS showed no sharp peaks indicating BUD was in molecularly dissolved state in optimized formulation.

\section{Powder X-ray Diffraction}

A further confirmation that drug is in structurally dissolved state was carried out by X-ray powder diffractograms. X-ray powder diffractogram for pure drug and solid SNEDDS is shown in Figure 4 The BUD displayed a peak of reduced crystallinity in SNEDDS.

\section{Scanning Electron Microscopy}

The scanning electron micrograph of solid SNEDDS shown in Figure 5 indicated that the powder particles had smooth surface and were spherical in shape.

\section{Drug Content in Solid SNEDDS}

The optimized batch (F3) contained $6 \mathrm{mg}$ drug out of total weight of $190 \mathrm{mg}$ of capsule contents.

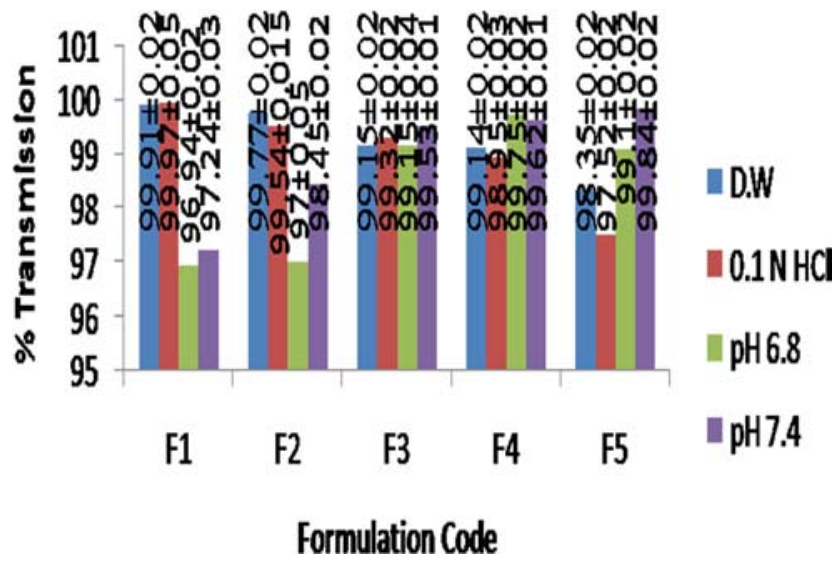

Figure 2: Percent transmission test at $628 \mathrm{~nm}$ in distilled water, $0.1 \mathrm{~N} \mathrm{HCl}$, phosphate buffer 6.8 , phosphate buffer 7.4.

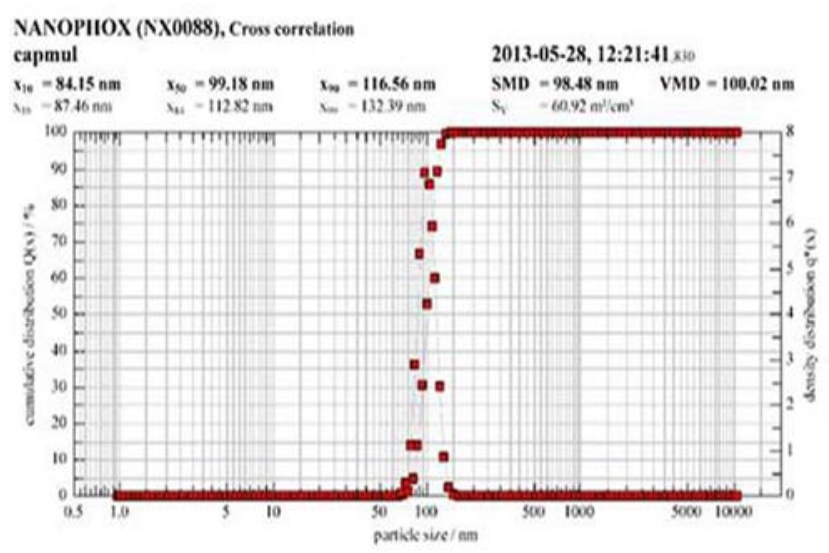

Figure 3: Droplet size distribution of Formulation code F3. The average droplet size of optimized formulation was found to be $116.52 \mathrm{~nm}$.

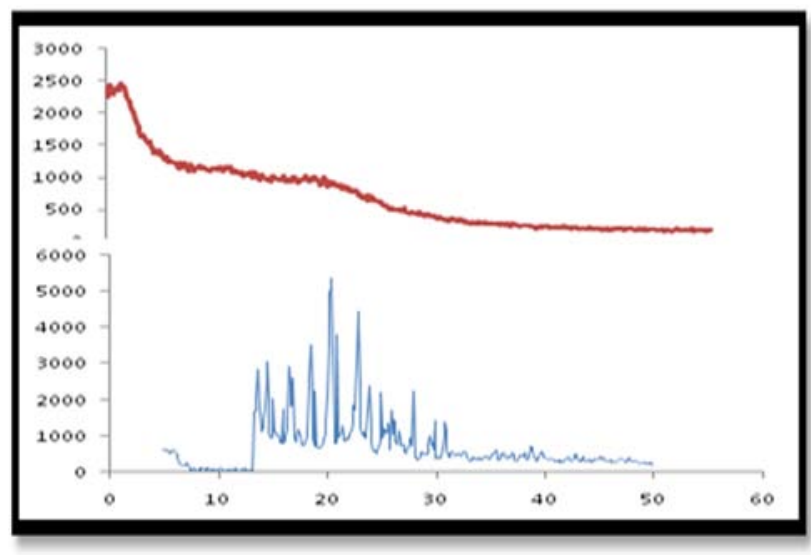

Figure-4 :X-ray powder diffract gram a) pure Budesonide and b) formulation F3 (solid SNEDDS)

\section{Transmission Test}

A transmittance of more than $97 \%$ in all the media tested indicated formation of nano emulsion with approximate particle size $100 \mathrm{~nm}$. 


\section{Table 4: Globule size and polydispersity index}

\begin{tabular}{|c|c|c|}
\hline $\begin{array}{c}\text { Formulation } \\
\text { Code }\end{array}$ & $\begin{array}{c}\text { Globule size }(\mathrm{nm}) \\
\text { Mean } \pm \text { S.D }\end{array}$ & $\begin{array}{c}\text { Polydispersity index } \\
\text { Mean } \pm \text { S.D }\end{array}$ \\
\hline F1 & $93.10 \pm 0.05$ & $0.069 \pm 0.001$ \\
\hline F2 & $93.54 \pm 0.045$ & $0.023 \pm 0.001$ \\
\hline F3 & $93.84 \pm 0.056$ & $0.128 \pm 0.001$ \\
\hline
\end{tabular}

S.D-Standard deviation

\begin{tabular}{|c|c|}
\hline \multicolumn{2}{|c|}{ Table 5: Optimized composition of SNEDDS } \\
\hline Ingredient & Quantity (mg) \\
\hline Capmul MCM C8 & 300 \\
\hline S-mix & 700 \\
\hline Drug & 06 \\
\hline Total & 1006 \\
\hline
\end{tabular}

S-mix-Surfactant-cosufactant mixture, SNEDDS-Self-nanoemulsifying drug delivery system

Table 6: Drug release kinetics for formulations

\begin{tabular}{|c|c|c|c|c|}
\hline Formulation & Best fit model & $\mathbf{N}$ & $\mathbf{k}$ & $\mathbf{R}$ \\
\hline F3 & peppas & 0.3907 & 0.0690 & 0.6472 \\
\hline Pure drug & peppas & 0.3338 & 0.0632 & 0.5949 \\
\hline
\end{tabular}

F3-Formulation code

\section{Mean Particle Size Determination}

The reconstituted solid SNEDDS and liquid SNEDDS were evaluated for its particle size and polydispersity index and it was found to be $116.52 \pm 0.75,0.289 \pm$ $0.0026 \& 98.48 \pm 0.77,0.326 \pm 0.0035$ respectively. Since, Aerosil was used as adsorbent in spray dryer this has resulted in the slight increase in particle size.

\section{Flow Properties}

The bulk density $(0.160 \pm 0.0084 \mathrm{~g} / \mathrm{ml})$ and tapped density $(0.183 \pm 0.058 \mathrm{~g} / \mathrm{ml})$ indicated that the prepared solid SNEDDS had higher bulk volume. The Carr's compressibility index was $12.56 \pm 0.040 \%$ while the Hausner's ratio was less than 1.25 .

\section{Drug Release Study}

Firstly the solid SNEDDS formulation filled into capsules then coating solution of $\mathrm{pH}$ sensitive polymer Eudragit S-100 sprayed on capsules with the help of spray gun in pan coater. These coated capsules remained intact in dissolution media used $0.1 \mathrm{~N} \mathrm{HCl}$ of $\mathrm{pH} 1.1$ and phosphate buffer solution of $\mathrm{pH}$ 6.8. As soon as the capsule comes in a contact with $\mathrm{pH} 7.4$ phosphate buffer, capsules began to dissolve to give immediate and complete release of BUD in $1 \mathrm{~h}$. As seen in Figure 6, a significantly higher amount of BUD (more than $95 \%$ ) was released at $6 \mathrm{~h}$ from the solid SNEDDS than pure form of drug $(57 \%)$. Self nano emulsifying drug delivery system highly contributed to enhanced solubility

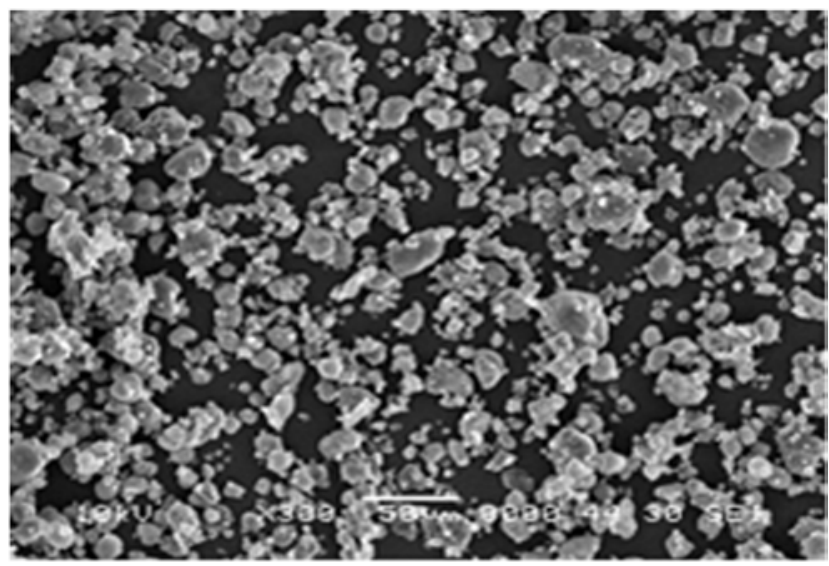

Figure 5 : SEM of solid SNEDDS of optimized formulation (F3).

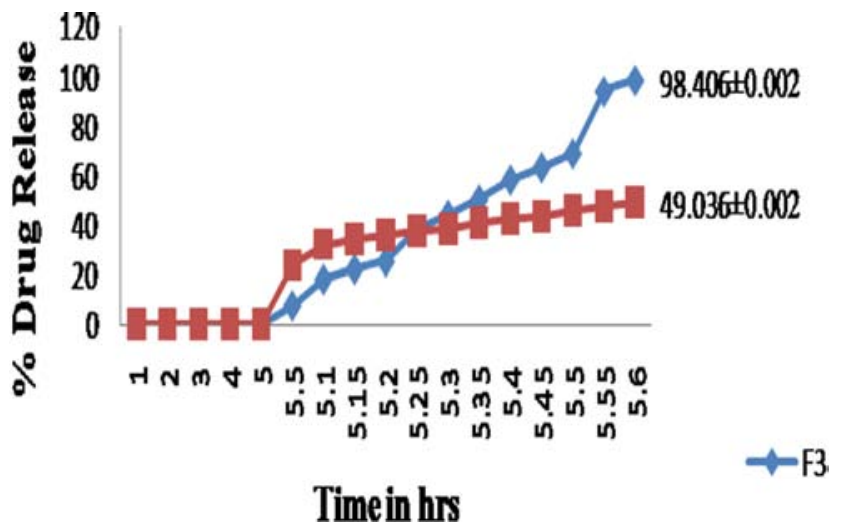

Figure 6 : In vitro drug release studies in $\mathrm{pH} 0.1 \mathrm{~N} \mathrm{HCl}$, phosphate buffer pH 6.8 and phosphate buffer $\mathrm{pH} 7.4$

of drug. Also, the ' $n$ ' value in all the cases was within 0.5 which meant that it followed Fickian diffusion (Table 6).

\section{Stability Study}

Solid SNEDDS on dilution did not show precipitation of drug and percent transmission was near $99 \%$ that indicated formation of nanoemulsion having globule size less than $100 \mathrm{~nm}$. No change was observed in globule size of solid SNEDDS. Thus, solid SNEDDS of BUD was physically and chemically stable. Results showed that there was no significant drug loss during the stability test periods.

\section{In vivo Study}

The histopathological sections of colon receiving different treatments are shown in Figure 7. The histopathological sections of normal colon (Figure 7-I) did not show any damage in microscopic examination (arrow-Mucosal and sub-mucosal layer). As seen in (Figure 7-II), histopathological section of severely damaged colon by TNBS, showed ulceration to mucosa and sub-mucosa layer of epithelium tissue (arrow). Figure 7-III showed tissue damages induced by administration of TNBS were diminished by after seven days treatment of SNEDDS formulation. 


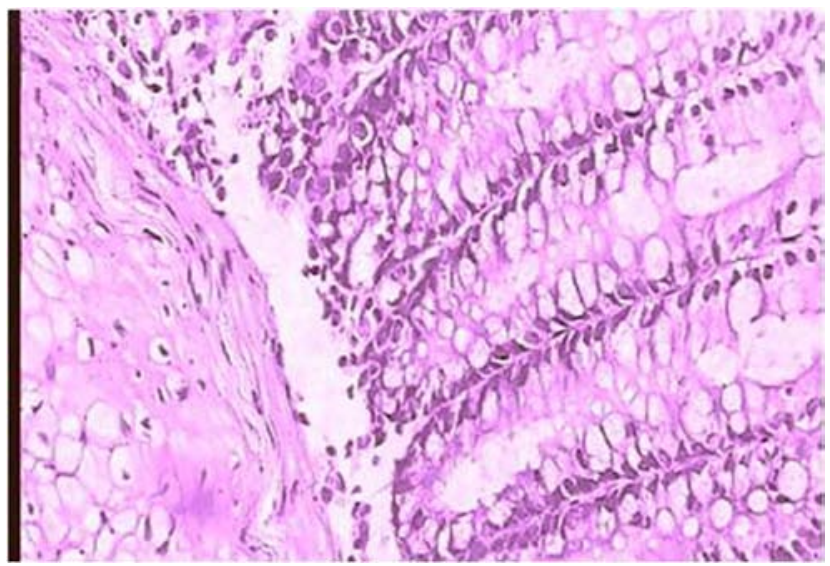

Figure 7 (a) : Representative histological appearance of rat colonic mucosa I-normal control (mucosal layer)

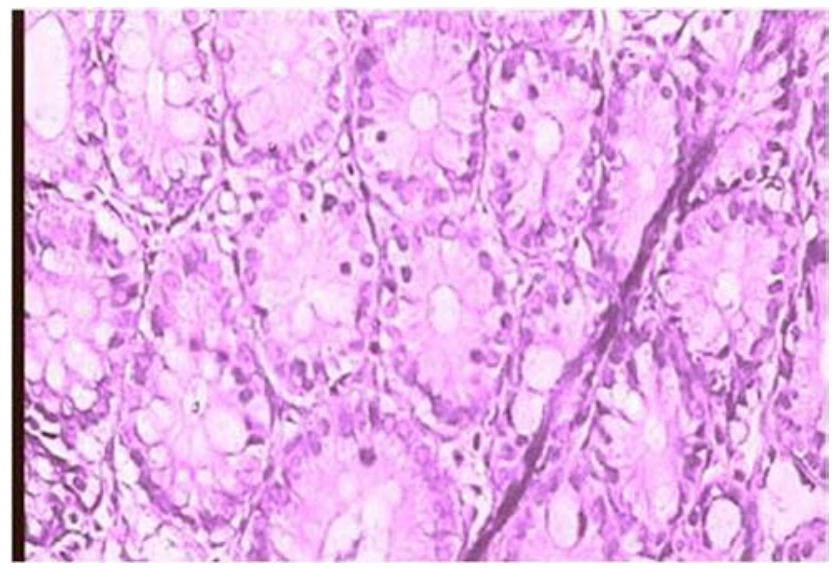

Figure 7 (b): Representative histological appearance of rat colonic mucosa I- normal control (submucosal layers).

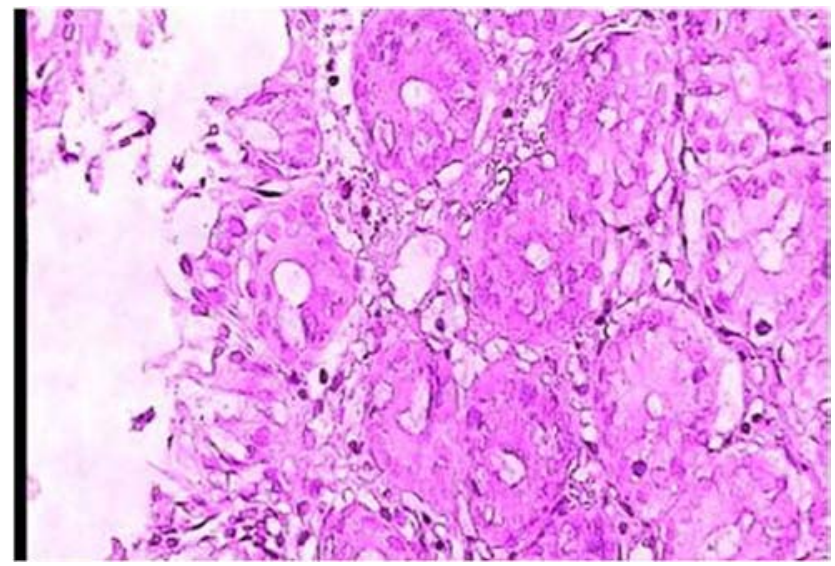

Figure 7 (d) : Representative histological appearance of rat colonic mucosa Il- colitis control (submucosal layers).

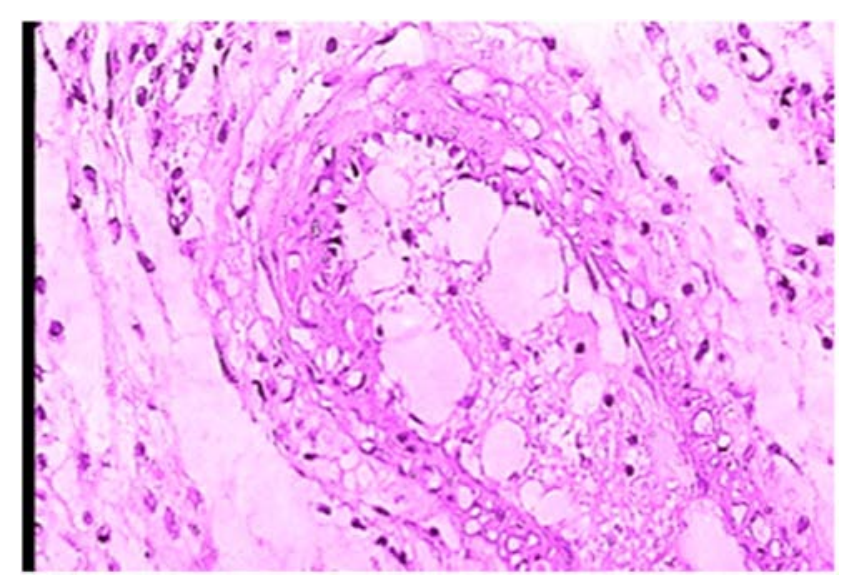

Figure 7 (c) : Representative histological appearance of rat colonic mucosa II- colitis control (mucosal layer).

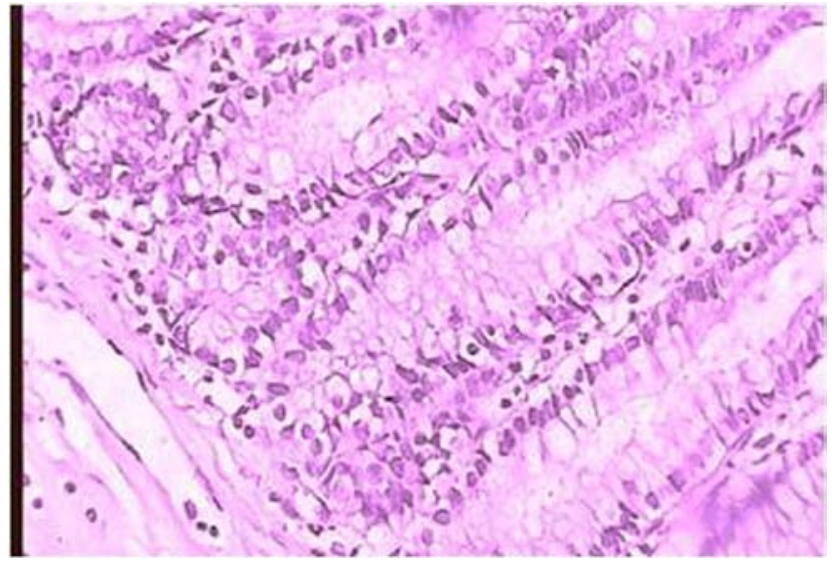

Figure 7 (e): Representative histological appearance of rat colonic mucosa III- budesonide enteric coated capsules (300 $\mu \mathrm{g} / \mathrm{kg} /$ day) (mucosal layers).

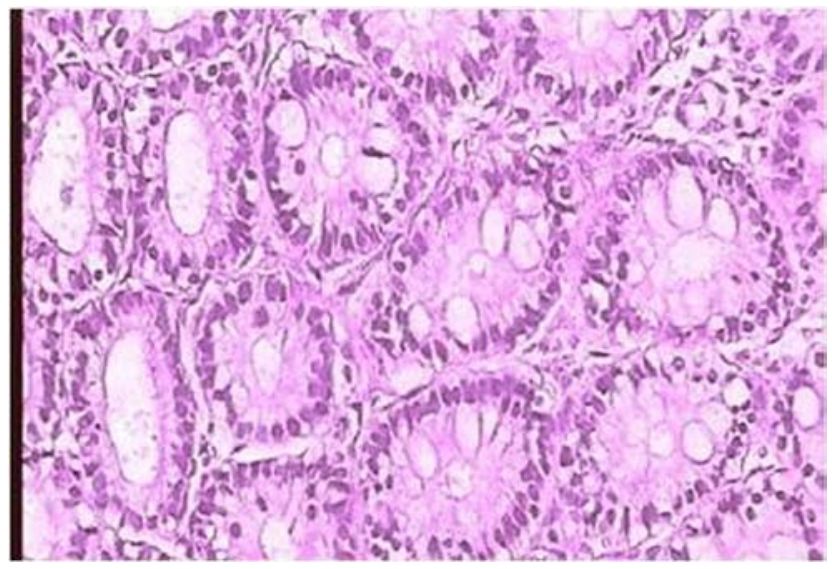

Figure 7 (f) : Representative histological appearance of rat colonic mucosa III- budesonide enteric coated capsules (300 $\mu \mathrm{g} / \mathrm{kg} /$ day) (submucosal layer). 
The histopathological study thus revealed that SNEDDS formulation demonstrated anti-inflammatory activity of BUD and thereby has potential in inflammatory bowel disease.

\section{CONCLUSION}

The SNEDDS of Budesonide were found to enhance the aqueous solubility. The SNEDDS was successfully targeted to the colon via encapsulating in a capsule coated by a $\mathrm{pH}$ dependent polymer. In vitro dissolution test studies demonstrated high release of drug from the formulated SNEDDS. In-vivo study concluded enhanced anti-inflammatory efficacy of budesonide loaded in SNEDDS. Thus, SNEDDS loaded with budesonide may prove better formulation for treatment of Ulcerative colitis. The present study has brought out the potential of enteric coated SNEDDS formulation in ulcerative colitis. Extensive clinical studies will further substantiate the merit of this novel formulation.

\section{ACKNOWLEDGEMENT}

The authors are thankful to the principal, progressive education society, Modern college of Pharmacy, Nigdi, Pune for providing well equipped laboratory and all other necessary facilities to carry out our research work.

\section{CONFLICT OF INTEREST}

The authors declare no conflict of interest.

\section{ABBREVIATION USED}

SNEDDS: Self-nanoemulsifying Drug Delivery System; BUD: Budesonide; S-Mix: Mixture of surfactant and Co-surfactant; W/W: Weight by weight; V/V: Volume by volume; nm: Nanometer; ml: Milliliters; HLB: Hydrophilic lipophilic balance; XRD: X-Ray diffractometer; DSC: Differential scanning calorimeter; TNBS: Trinitrobenzenesulphonic acid; NE: Nanoemulsion area; NO: Not Obtained; F1-F5: Formulation code.

\section{REFERENCES}

1. http://www.drugbank.ca

2. Shukla JB, Koli AR, Ranch KM, Parikh RK. Self-micro emulsifying drug delivery system. An international journal of pharmaceutical sciences. 2010;1(2):13-33.
3. Constantinides PP. Lipid microemulsions for improving drug dissolution and oral absorption: physical and biopharmaceutical aspects. Pharmaceutical research. 1995;12(11):1561-72. https://doi.org/10.1023/A:1016268311867; PMid:8592652.

4. Cortesi R, Esposito E, Maietti A, Menegatti E, Nastruzzi C. Formulation study for the antitumor drug camptothecin: liposomes, micellar solutions and a microemulsion. International journal of pharmaceutics. 1997;159(1):95-103. https://doi.org/10.1016/S0378-5173(97)00275-5.

5. Kumar KV, Sivakumar T, Mani TT. Colon targeting drug delivery system: A review on recent approaches. Int J Pharm Biomed Sci. 2011;2(1):11-9.

6. Sreelatha D, Brahma CK. Colon targeted drug delivery-a review on primary and novel approaches. Journal of Global Trends in Pharmaceutical Sciences. 2013;4(3):1174-83.

7. Zhang L, Zhu W, Yang C, Guo H, Yu A, et al. A novel folate-modified selfmicroemulsifying drug delivery system of curcumin for colon targeting. Int $\mathrm{J}$ Nanomedicine. 2012;7:151-62. PMid:22275831 PMCid:PMC3263408.

8. Borhade V, Nair H, Hegde D. Design and evaluation of self-microemulsifying drug delivery system (SMEDDS) of tacrolimus. Aaps Pharmscitech. 2008; 9(1):13-21. https://doi.org/10.1208/s12249-007-9014-8; PMid:18446456 PMCid:PMC2976874.

9. Singh AK, Chaurasiya A, Jain GK, Awasthi A, Asati D, et al. High performance liquid chromatography method for the pharmacokinetic study of Bicalutamide SMEDDS and suspension formulations after oral administration to rats. Talanta. 2009;78(4):1310-4. https://doi.org/10.1016/j.talanta.2009.01.058; PMid:19362193.

10. Balakrishnan $\mathrm{P}$, Lee $\mathrm{BJ}$, Oh $\mathrm{DH}$, Kim JO, Hong MJ, et al. Enhanced oral bioavailability of dexibuprofen by a novel solid self-emulsifying drug delivery system (SEDDS). European Journal of Pharmaceutics and Biopharmaceutics. 2009;72(3):539-45. https://doi.org/10.1016/j. ejpb.2009.03.001; PMid:19298857.

11. Yi T, Wan J, Xu H, Yang $X$. A new solid self-microemulsifying formulation prepared by spray-drying to improve the oral bioavailability of poorly water soluble drugs. European Journal of Pharmaceutics and Biopharmaceutics. 2008;70(2):439-44. https://doi.org/10.1016/j.ejpb.2008.05.001; PMid:18603415.

12. Varshosaz J, Emami J, Tavakoli N, Minaiyan M, Rahmani N, et al. Pectin film coated pellets for colon-targeted delivery of budesonide: In-vitro/in-vivo evaluation in induced ulcerative colitis in rat. Iranian journal of pharmaceutical research: IJPR. 2012;11(3):733. PMid:24250500 PMCid:PMC3813129

13. Pouton CW, Porter CJ. Formulation of lipid-based delivery systems for oral administration: materials, methods and strategies. Advanced Drug Delivery Reviews. 2008;60(6):625-37. https://doi.org/10.1016/j.addr.2007.10.010; PMid:18068260.

14. Jaiswal P, Aggarwal G. Bioavailability Enhancdement Of Poorly Soluble Drugs By Smedds: A Review. Journal of drug delivery and therapeutics. 2013;3(1).

15. Kumar M, Pathak K, Misra A. Formulation and characterization of nanoemulsion-based drug delivery system of risperidone. Drug development and industrial pharmacy. 2009;35(4):387-95. https://doi. org/10.1080/03639040802363704; PMid:19016058.

16. Nidhi M, Shikha S. New Strategy for Solubilization of poorly soluble drugSEDDS. Der Pharmacia Lettre. 2009;1(2):60-7.

17. Hauss DJ, Fogal SE, Ficorilli JV, Price CA, Roy T, et al. Lipid-based delivery systems for improving the bioavailability and lymphatic transport of a poorly water-soluble LTB4 inhibitor. Journal of pharmaceutical sciences. 1998;87(2):164-9. https://doi.org/10.1021/js970300n; PMid:9519148. 


\section{PICTORIAL ABSTRACT}

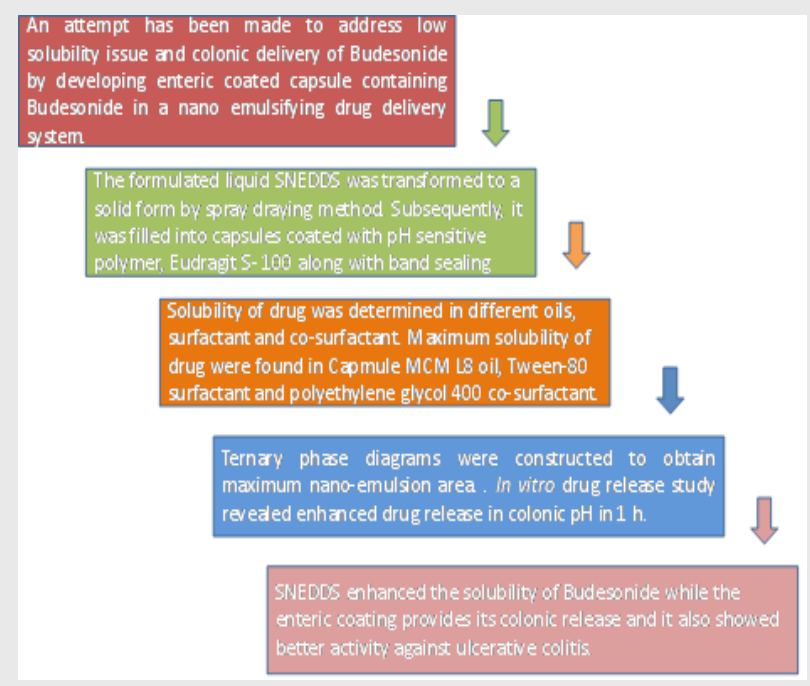

\section{About Authors}
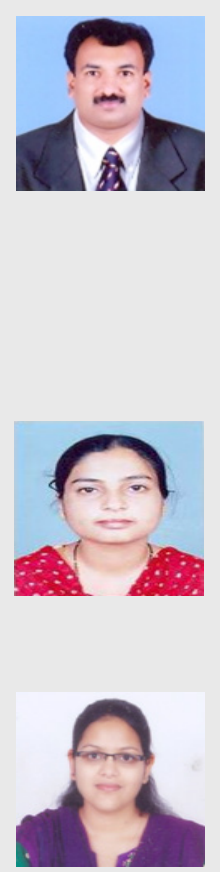

\section{SUMMARY}

- The Self-nanoemulsifying Drug Delivery System was developed for colonic delivery of budesonide drug as novel technique to efficiently improve drug solubility and enhance bioavailability.

- The drug Solubility is an important parameter which was determined in different oils, surfactants and co-surfactants. Ternary phase diagrams were constructed to obtain maximum nano-emulsion area. SNEDDS containing Capmule ${ }^{\circledR}$ MCM L8 as oil, Tween80 as surfactant and polyethylene glycol 400 as co-surfactant were formulated to get maximum nano-emulsion in the phase diagram

- $\quad$ The formulated liquid SNEDDS was transformed to a solid form by spray draying method. Subsequently, it was filled into capsules coated with $\mathrm{pH}$ sensitive polymer, Eudragit S- 100 along with band sealing.

- The prepared formulations were characterized for physicochemical parameters and In vitro drug release study. The optimized SNEDDS (particle size $116.32 \mathrm{~nm}$ ) revealed enhanced drug release in colonic $\mathrm{pH}$ as compared to pure drug.

- The developed SNEDDS of budesonide also demonstrated better activity against ulcerative colitis as evidenced by the gradually diminishing morphological damages in the histopathological studies in the TNBS induced ulcerative colitis in rats. Thus, SNEDDS enhanced the solubility of Budesonide while the enteric coating provides its colonic release.

Dr. Pravin D. Chaudhari: Is presently working as Principal \& Professor of Pharmaceutics at Modern College of Pharmacy, Pune (MS), INDIA. \& President of Association of Pharmaceutical Teachers of India. He has completed M. Pharm from NDMVP'S College of Pharmacy, Nashik and doctoral degree from Bundelkhand University. He has around 18 years of Professional experience. He has filled Two Patent and has published more than 116 research papers. He was worked as a Dean, Faculty of Pharmaceutical Sciences, University of Pune. He has received prestigious Dr. R.L. Nicore award 2009 and IDMA award 2011 for best research paper. He is actively associated with various professional bodies. He is a recipient of MPA award 2008 by Maharashtra Pharmacist Association and Rashtriya Gaurav Award 2010 by Indian International Friendship society, New Delhi for his outstanding performance, remarkable role and meritorious services for pharmacy profession.

Dr. Karimunnisa S. shaikh: Obtained her PhD in pharmacy faculty from Bharati Vidyapeeth Deemed University, Pune, Maharashtra. Currently she is working as Associate Professor \& Head of Quality Assurance Techniques department at Modern College of Pharmacy, Nigdi, Pune. She has vast experience in teaching and research in field of Nanotechnology. She has guided many post graduate students as well as ph.D students also. She has contributed as author for many publications in international, national journals along with paper presentation in many conferences.

Ms. Nikita M. Gaikwad: She obtained her Master degree in pharmacy faculty from Progressive Education Society, Modern college of pharmacy, Nigdi, Pune, Maharashtra. Currently working as Assistant Professor at Modern College of Pharmacy, Nigdi, Pune in the department of Quality Assurance Techniques. She has good experience in teaching and research in field of pharmaceutics also contributed as author for international journal.

Cite this article: Gaikwad NM, Shaikh KS, Chaudhari PD. Development and Evaluation of a System for Colonic Delivery of Budesonide. Indian J of Pharmaceutical Education and Research. 2017;51(4):551-61. 